Article

\title{
Vegetation Changes along the Qinghai-Tibet Plateau Engineering Corridor Since 2000 Induced by Climate Change and Human Activities
}

\author{
Yi Song ${ }^{1, *}$, Long Jin ${ }^{2, *}$ and Haibo Wang ${ }^{3}$ \\ 1 State Key Laboratory of Loess and Quaternary Geology, Institute of Earth Environment, \\ Chinese Academy of Sciences, Xi'an 710061, China \\ 2 Key Laboratory of Highway Construction \& Maintenance Technology in Permafrost Regions, \\ Ministry of Transport, CCCC First Highway Consultants Co., Ltd., Xi'an 710065, China \\ 3 Northwest Institute of Eco-Environment and Resources, Chinese Academy of Sciences, Lanzhou 730000, \\ China; whb@lzb.ac.cn \\ * Correspondence: songyi@ieecas.cn (Y.S.); jinl@ccroad.com.cn (L.J.); Tel.: +86-29-6233-6290 (Y.S.); \\ +86-186-2963-8591 (L.J.)
}

Received: 21 September 2017; Accepted: 10 January 2018; Published: 12 January 2018

\begin{abstract}
The Qinghai-Tibet (QT) Plateau Engineering Corridor is located in the hinterland of the QT Plateau, which is highly sensitive to global climate change. Climate change causes permafrost degradation, which subsequently affects vegetation growth. This study focused on the vegetation dynamics and their relationships with climate change and human activities in the region surrounding the QT Plateau Engineering Corridor. The vegetation changes were inferred by applying trend analysis, the Mann-Kendall trend test and abrupt change analysis. Six key regions, each containing 40 nested quadrats that ranged in size from $500 \times 500 \mathrm{~m}$ to $20 \times 20 \mathrm{~km}$, were selected to determine the spatial scales of the impacts from different factors. Cumulative growing season integrated enhanced vegetation index (CGSIEVI) values were calculated for each of the nested quadrats of different sizes to indicate the overall vegetation state over the entire year at different spatial scales. The impacts from human activities, a sudden increase in precipitation and permafrost degradation were quantified at different spatial scales using the CGSIEVI values and meteorological data based on the double mass curve method. Three conclusions were derived. First, the vegetation displayed a significant increasing trend over $23.6 \%$ of the study area. The areas displaying increases were mainly distributed in the Hoh Xil. Of the area where the vegetation displayed a significant decreasing trend, $72.4 \%$ was made up of alpine meadows. Second, more vegetation, especially the alpine meadows, has begun to degenerate or experience more rapid degradation since 2007 due to permafrost degradation and overgrazing. Finally, an active layer depth of $3 \mathrm{~m}$ to $3.2 \mathrm{~m}$ represents a limiting depth for alpine meadows.
\end{abstract}

Keywords: permafrost degradation; human activities; vegetation change; scale effect; Qinghai-Tibet Plateau Engineering Corridor

\section{Introduction}

Vegetation makes up the main part of terrestrial ecosystems [1] and is an important element of energy exchanges, the water cycle and biogeochemical cycles at the Earth's surface. Vegetation plays a key role in the flow of matter and energy among the pedosphere, hydrosphere and atmosphere $[1,2]$. Vegetation change has been and will be a key issue in global changes involving terrestrial ecosystems as it is sensitive to climate change [3,4]. The Qinghai-Tibet (QT) Plateau is one of the most sensitive areas in terms of its response to global climate change because of its unique topography [5] and the widespread occurrence of permafrost [6,7] and is recognized as a hotspot for coupled studies 
of global terrestrial ecosystem change and global climate change [8-10]. The alpine cold grassland ecosystems found within the permafrost area on the QT Plateau are closely associated with permafrost conditions [11].

Some studies have indicated that the permafrost on the QT Plateau has degraded in recent decades $[12,13]$. The mean active layer depth-the thickness of the layer of the ground subject to annual thawing and freezing in areas underlain by permafrost-around the Beilu River increased by at least $42 \mathrm{~cm}$ from 2003 to 2016 [13]. Between 2002 and 2012, the spring onset of soil thawing at a depth of $50 \mathrm{~cm}$ advanced by approximately 20 days within alpine meadows and 18 days within alpine steppes [12]. From 1987 to 2008, there was a pattern of earlier thawing and later freezing due to climate warming, especially in seasonally frozen ground and permafrost regions with high ground temperatures [14].

Peng et al. analyzed the trends in vegetation dynamics (changes in greenness) on the QT Plateau during 1982 to 2003 using the Advanced Very High Resolution Radiometer (AVHRR) global inventory modelling and mapping studies (GIMMS) normalized difference vegetation index (NDVI) dataset. Most of the vegetation $(82.4 \%$ ) showed significant increases, although nearly $50 \%$ of the broadleaf forest experienced degradation [10]. However, the increases in temperature since 2000 have caused the permafrost to thaw. When permafrost thaws, the large volume of water that had been stored in frozen soil is released and lost to evaporation. In addition, topsoil water infiltration increases as the thawed soil loses the ability to block the infiltration of water and becomes strongly hydraulically conductive. If precipitation cannot balance out the moisture loss, the vegetation retreats and desertification occurs. Permafrost degradation has caused regional desertification in the grazing regions of the QT Plateau since $2000[15,16]$. Studies have also asserted that the alpine cold grassland ecosystems will experience further degradation if the global climate continues to warm and precipitation does not increase significantly. One of the primary objectives of our study was to quantify the vegetation changes on the QT Plateau since 2000.

In addition to climate change, human activities can affect vegetation growth. From 2000 to 2015, the QT highway underwent two large-scale improvement projects. Construction of the second phase of the QT railway began in June 2001 and was officially opened to traffic in July 2006. How much have these engineering activities contributed to the observed vegetation changes? The QT Plateau is one of the most important grazing regions in China. What role has animal husbandry played in the process of vegetation change? We assessed the impact of linear infrastructure projects and animal husbandry on vegetation changes in our study.

The area surrounding the QT Plateau Engineering Corridor, which is located in the hinterland of the QT Plateau, was selected as our study area. The primary objectives of our study were (1) to characterize the vegetation changes within our study area from 2000 to 2016; (2) to analyze the relationships between climate change, the permafrost environment, vegetation growth and human activities; and (3) to quantify the impacts from different factors to the vegetation changes and determine the spatial scales of these impacts.

\section{Materials and Methods}

\subsection{Study Area}

Our study area (the surrounding area of the QT Plateau Engineering Corridor) is located in the hinterland of the QT plateau where permafrost and frozen ground are widely distributed (see Figure 1). Approximately half (52.9\%) of the study area is covered with alpine meadows dominated by Kobresia spp.—such as Kobresia pygmaea—and forbs—such as Polygomum sphaerostachyum [17]. The alpine meadows are mainly distributed in the Tanglha Mountains, the south of the Tanglha Mountains and the regions of permafrost thawing around rivers. Over a quarter $(28 \%)$ of our study area is covered with alpine steppes dominated by grasses—such as Stipa purpurea-and Carex spp.-such as Carex moorcroftii. The alpine steppes are mainly distributed in the Hoh Xil. Much of the remainder 
$(13.8 \%)$ of the study area at relatively high elevations is covered with alpine cushion vegetation-such as Arenaria kansuensis and Rhodiola spp. cushion vegetation-and sparse alpine vegetation-such as Saussurea medusa and Saussurea spp. sparse vegetation. Less than 1\% of the study area at relatively low elevations is covered with subalpine broadleaf deciduous scrub vegetation. Over half of our study area is covered with alpine meadows, which are the main source of food for herbivores in this region. Cows, sheep and goats are the main herbivores in our study area.
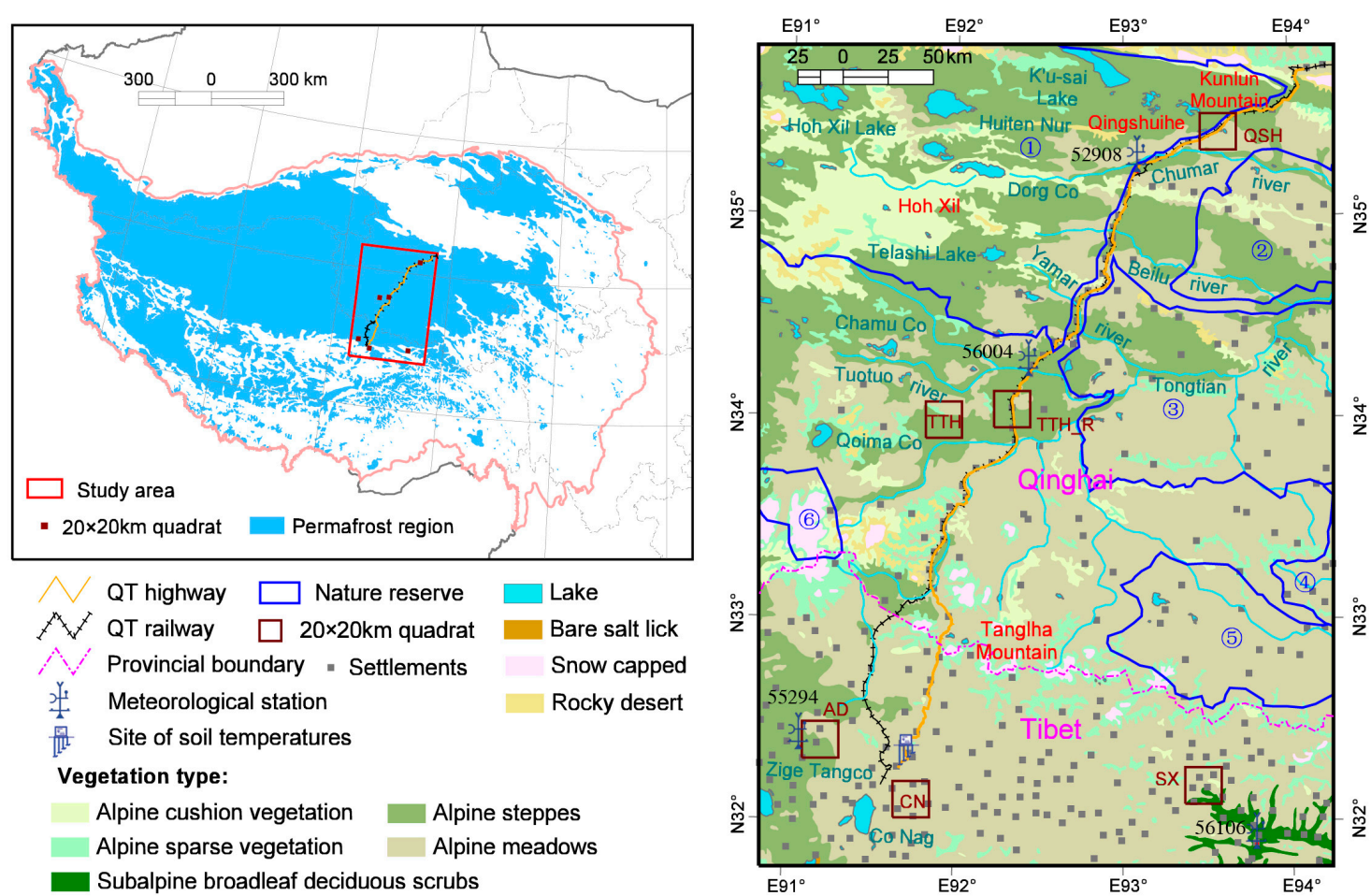

Figure 1. The vegetation types from Hou et al. [17], distribution of permafrost from Li and Cheng [18] and analyzed quadrats in our study area. Note: the six reserves are the (1) Hoh Xil nature reserve,

(2) Chumar River wildlife reserve, (3) Soga wildlife reserve, (4) Guozongmucha wetland reserve,

(5) Dangqu wetland reserve and (6) Gradanton Glacier reserve.

From 2000 to 2016, the QT highway underwent two large-scale improvement projects. One of these projects took place from 2002-2004, whereas the other took place from 2008-2010. During the first renovation, the subgrade was reinforced between April to September in the first two years and the pavement was rebuilt in the third year of renovation. The construction of the second phase of the QT railway began in June 2001 and was officially opened to traffic in July 2006. The QT railway parallels the QT highway as far as Tanglha Pass.

\subsection{Data}

\subsubsection{Remotely Sensed Vegetation Index Dataset}

Moderate-resolution Imaging Spectrometer (MODIS) Enhanced Vegetation Index (EVI) data with a spatial resolution of $250 \times 250 \mathrm{~m}$ and a temporal resolution of 16 days that covered the period from 2000 to 2016 were used in this study. The MODIS EVI dataset (MOD13Q1) was downloaded from the Land Processes Distributed Active Archive Center (LPDAAC) of NASA.

\subsubsection{In Situ Meteorological Data and Soil Temperature Observations}

Daily observations of temperature and precipitation covering the period from 2000 to 2015 were downloaded from the National Meteorological Information Center (NMIC) of China Meteorological 
Administration (CMA). These data were measured at four national meteorological stations at the following locations: near the Tuotuo River (station id: 56004; $21 \mathrm{~km}$ and $52 \mathrm{~km}$ from the central point of the TTH_R quadrat and TTH quadrat, respectively), at Wudaoliang (52908; $49 \mathrm{~km}$ from the central point of the QSH quadrat), in Amdo County (55294; $11 \mathrm{~km}$ and $67 \mathrm{~km}$ from the central point of the AD quadrat and CN quadrat, respectively) and in Suoxian County (56106; $40 \mathrm{~km}$ from the central point of the SX quadrat), respectively (see Figure 1).

To investigate the long-term changes in permafrost, soil temperatures were measured near Amdo County $\left(91^{\circ} 42^{\prime} 55.32^{\prime \prime} \mathrm{E}, 32^{\circ} 23^{\prime} 27.71^{\prime \prime} \mathrm{N}\right.$, see Figure 1$)$ at depths of $1.15 \mathrm{~m}$ to $10.65 \mathrm{~m}$ using 20 thermal probes with a precision of $\pm 0.02{ }^{\circ} \mathrm{C}$ (see Figure S1 in Supplementary Material). These measurements were made twice a month.

\subsubsection{Yearly Livestock Statistical Data}

Yearly statistical data on the number of livestock in Qinghai and Tibet that covered the years 2000 to 2015 were downloaded from the National Bureau of Statistics of China. The yearly stock volumes of cows, sheep, goats and other herbivores (see Figure S3 in Supplementary Material) such as horses and camels, were analyzed in this study. The yearly stock volume of total herbivorous livestock in Qinghai Province (QH) was approximately 22 million before 2005 (see Figure S2 in Supplementary Materials). Due to the government macro-control and the adjustments in agricultural policy in 2006, the stock volume of goats and sheep decreased by 2 million and the stock volume of total livestock in $\mathrm{QH}$ decreased to 20 million or fewer.

\subsection{Data Processing}

\subsubsection{Remotely Sensed Vegetation Index Data Processing}

The seasonal integrated vegetation index is widely used in vegetation change studies [19] as an annual index that indicates the status of vegetation growth for a whole year. In our study, we calculated growing season integrated enhanced vegetation index (GSIEVI) values to analyze the trends in vegetation change. The cumulative GSIEVI (CGSIEVI) within particular areas was calculated for each of the nested quadrats of different sizes to show the overall vegetation state over the whole year.

The EVI is expressed on a scale of -1 to +1 . EVI values below 0.1 correspond to snow, inland water bodies, deserts and bare soil; as the EVI increases above 0.1, it indicates greater amounts of green vegetation. The GSIEVI was defined as the sum of the EVI values that exceeded the critical value of EVI > 0.1 for each pixel during April to October. The GSIEVI was used in the trend analysis (Section 2.4) as an annual index of vegetation growth at the pixel scale.

In our study, we selected six key regions, which included two roadside regions and four other typical regions (see Figure 1). The two roadside regions were located in Qingshuihe (QSH) and southeast of the Tuotuo River (TTH_R). The other four typical regions were located near Amdo County (AD), east of Co. Nag Lake (CN), near Suoxian County (SX) and west of TTH_R (TTH). We designed 40 nested quadrats of different sizes in each key region to analyze the drivers of vegetation changes by using a remotely sensed dataset. The sizes of the quadrats ranged from $500 \times 500 \mathrm{~m}$ to $20 \times 20 \mathrm{~km}$.

Due to the sparse vegetation cover in the study area, the use of average GSIEVI values to characterize particular areas are weakened by the low GSIEVI values of bare soil. The CGSIEVI was defined as the cumulated value of all GSIEVI values within a certain area and used as an annual index of the overall vegetation state. The CGSIEVI value of each of the nested quadrats of different sizes was calculated and the resulting values were used to analyze the drivers of vegetation changes (Section 2.5).

To determine the spatial scales of the influence from renovation and construction of the QT highway and railway on vegetation growth, we selected two sets of steeled nested quadrats near the QSH and TTH_R quadrats. The central point of each set of steeled nested quadrats was $15 \mathrm{~km}$ away from the highway and railway, thus the vegetation within the two set of steeled nested quadrats was 
not affected by engineering activities. We used these two sets of steeled nested quadrats as nature quadrats to compare with the roadside quadrats, the QSH and TTH_R quadrats. We calculated the cumulative EVI (CEVI) values within the roadside quadrats and nature quadrats (see Section 3.3.1).

\subsubsection{In Situ Data Processing}

The yearly active cumulative temperatures above $0{ }^{\circ} \mathrm{C}\left(A T_{y}\right)$ were calculated for the four meteorological stations. The daily rainfall during the growing season (April to September) and the snow that fell during the preceding winter (October to March) were added together and used as the yearly precipitation $\left(P_{y}\right)$. The $A T_{y}$ and $P_{y}$ are presented in Figure $\mathrm{S} 3$ in the Supplementary Material.

The active layer depth of a certain year was defined as the maximum depth at which the ground temperature is zero in this year. The active layer depths from 1998 to 2014 were calculated from the ground temperature observations.

\subsection{Analyses of Vegetation Change}

\subsubsection{Trend Analysis}

Trend analysis was used to assess the greenness rate of change (GRC). Stow et al. defined the GRC as the slope of the line that provides the best fit (as assessed using the least squares methods) to seasonally integrated normalized difference vegetation index (SINDVI) values over the entire time period under study $[19,20]$. In our study, EVI was used instead of NDVI to calculate the integrated vegetation index during the growing season (GSIEVI). GRC in our study was calculated based on the GSIEVI values. This trend index can be expressed as follows:

$$
\mathrm{GRC}=\frac{n \times \sum_{i=1}^{n} i \times G S I E V I_{i}-\sum_{i=1}^{n} i \sum_{i=1}^{n} \operatorname{GSIEVI}_{i}}{n \times \sum_{i=1}^{n} i^{2}-\left(\sum_{i=1}^{n} i\right)^{2}}
$$

where $n$ is the number of years from 2000 to 2016 (17 years in total) and GSIEVI $I_{i}$ is the GSIEVI for the $i$ th year. Hence, the range of GSIEVI change can be expressed as follows:

$$
\text { Range }=\text { GRC } \times(n-1)
$$

In pixels where the Range was greater than 0 , the GSIEVI values displayed increasing trends over the past 17 years. The GSIEVI values of the other grid cells displayed decreasing trends. The ratio of the range of the GSIEVI values to the GSIEVI value in 2000, expressed as a percentage, was then calculated for each pixel as follows:

$$
\text { Percentage }=100 \times \text { Range } / \text { GSIEVI } 2000
$$

\subsubsection{Significance of Vegetation Change}

The Mann-Kendall (MK) trend test was employed to assess the significance of the GSIEVI trends from 2000 to 2016. The MK test is a non-parametric statistical test that assesses the significance of a change trend within a time series in the absence of any seasonal variation or other cycles and has been widely used in detecting trends in hydrologic, climatic and environmental factors [21-23]. For an independently distributed time series $\left(x_{1}, x_{2}, \ldots, x_{n}\right)$, the null hypothesis $\left(H_{0}\right)$ of the MK test is that no trend is present. The significance of change trend was determined according to the test statistic $S$ (if $n \leq 8$ ) or $Z$ (if $n>8$ ), which were calculated as follows:

$$
S=\sum_{i=1}^{n-1} \sum_{j-i+1}^{n} \operatorname{sgn}\left(x_{j}-x_{i}\right)
$$




$$
\begin{gathered}
\operatorname{sgn}\left(x_{j}-x_{i}\right)= \begin{cases}1 & \text { if }\left(x_{j}-x_{i}\right)>0 \\
0 & \text { if }\left(x_{j}-x_{i}\right)=0 \\
-1 & \text { if }\left(x_{j}-x_{i}\right)<0\end{cases} \\
\operatorname{Var}(S)=\frac{1}{18}\left[n(n-1)(2 n+5)-\sum_{p=1}^{q} t_{p}\left(t_{p}-1\right)\left(2 t_{p}+5\right)\right] \\
Z= \begin{cases}\frac{S-1}{\sqrt{\operatorname{Var}(S)}} & \text { if } S>0 \\
0 & \text { if } S=0 \\
\frac{S+1}{\sqrt{\operatorname{Var}(S)}} & \text { if } S<0\end{cases}
\end{gathered}
$$

where $x_{j}$ and $x_{i}$ are the GSIEVI values in the $j$ th and $i$ th years $(j>i)$, respectively. The GSIEVI values that were the same were grouped into one tier. The GSIEVI values that had unique values were grouped by themselves. $t_{p}$ indicates the extent of any given tier and $q$ is the number of tiers. A positive value of $Z$ or $S$ indicates an increasing trend, whereas a negative value indicates a decreasing trend. If the absolute value $|Z|>Z_{(1-\alpha / 2)}$, the $H_{0}$ was rejected and the trend in the GSIEVI values was determined to be statistically significant at the confidence level $\alpha$ (in the MK test, $\alpha$ was set to $0.01,0.05,0.1$ and 0.15 ).

\subsubsection{Abrupt Change Test}

The Pettitt test [24] is also a non-parametric test and is typically applied to detect abrupt change points in time series of hydrological data. Here, we used the Pettitt test to identify the year at which an abrupt change occurred in the series of GSIEVI and to detect the significance of this change. The Pettitt test splits a time series $\left(x_{1}, x_{2}, \ldots, x_{n}\right)$ into two sub-samples $\left(x_{1}, x_{2}, \ldots, x_{\tau}\right.$ and $x_{\tau+1}, x_{\tau+2}$, $\left.\ldots, x_{n}\right)$ at time $\tau$. The $k(\tau)$ statistic can be computed as follows:

$$
k_{\tau}=\sum_{i=1}^{\tau} \sum_{j=1}^{n} \operatorname{sgn}\left(x_{i}-x_{j}\right)
$$

where sgn is defined in Equation (5). The abrupt change most likely occurred at the time when the absolute value of $k_{\tau}$ reaches its maximum value.

$$
K=\max _{1 \leq \tau \leq n}\left|k_{\tau}\right|
$$

The significance of the abrupt change was approximated by:

$$
p \approx 2 \times \exp \left(\frac{-6 K^{2}}{n^{3}+n^{2}}\right)
$$

A significance level of 0.05 was used in the Pettitt test. If $p<0.05$, an abrupt change occurred at a significance level of 0.05 .

\subsection{The Driving Force Analysis of Vegetation Change}

\subsubsection{Correlation Analysis at Different Spatial Scales}

The partial correlations and multiple correlations between the CGSIEVI values and the two climate factors $A T_{y}$ and $P_{y}$ were calculated. Within our study area, we designed six groups of nested quadrats of different sizes for the six key regions. Each group contained 40 nested quadrats of different sizes. The correlations were calculated for each of the quadrats. 


\subsubsection{Double Mass Analysis}

A double mass curve (DMC) is a plot of the cumulative values of one variable against the cumulative values of another quantity over the same time period. This procedure is typically performed using precipitation data and many other types of hydrological data such as sediment transport $[25,26]$ and reservoir sedimentation [27]. The DMC is based on the hypothesis that the two variables are proportional. When the cumulative values of two quantities are plotted and the data fall along a straight line, it indicates that the two variables have the same physical cause or a clear causal relationship. The slope of the line represents the constant of proportionality between the two quantities and a break in slope indicates a change in the constant of proportionality. Thus, in the application of the DMC method, the two variables have either the same physical cause or an obvious causal relationship.

Two climate factors, temperature and precipitation, were considered in our study. The $A T_{y}$ and $P_{y}$ were calculated using the daily temperature and precipitation data obtained from the National Meteorological Information Center. We calculated the partial correlations between the CGSIEVI values and the two main climate factors. If the two factors showed significant correlations simultaneously, we used the linear regression method to reduce the dimensionality of the data. The linear regression equation was established for the CGSIEVI values using $A T_{y}$ and $P_{y}$. We calculated an integrated climate index $(C I)$ using the standard regression coefficients as follows:

$$
C I=a \times A T_{y}+b \times P_{y}+c
$$

where $a$ and $b$ are the standard regression coefficients for $A T_{y}$ and $P_{y}$, respectively. We then plotted the DMCs using the cumulative values of the CGSIEVI at different spatial scales and the cumulative values of the integrated CI. If one of the two factors showed a significant correlation individually, the DMCs were generated using the cumulative values of the CGSIEVI at different spatial scales and the cumulative values of the climate factor that showed a significant correlation with the CGSIEVI. Based on the DMCs, we quantified the impacts from different factors at different spatial scales. A break in slope indicated a change in the constant of proportionality. The impacts from non-climatic factors to the vegetation changes were quantified as the percentage of the changes caused by external disturbances in the estimated amount that external forces did not occur. The DMCs for quadrats in the QSH key region at different spatial scales $(500 \times 500 \mathrm{~m}, 10 \times 10 \mathrm{~km}$ and $20 \times 20 \mathrm{~km})$ are shown in the Figure S4 in Supplementary Material.

\section{Results}

\subsection{Vegetation Changes during the Past 17 Years}

Figure 2a shows patterns in the trend index GRC, which was calculated according to Equation (1), in our study area from 2000 to 2016. The green and red colors indicate increases and decreases in vegetation; darker colors indicate greater changes, respectively; more saturated colors indicate greater changes. During the past 17 years, most of the vegetation in the Hoh Xil increased, with a significance level of 0.05 (Figure 2b). Figure 2c shows the percentage of the GSIEVI values of 2000 represented by the range of the GSIEVI changes. The percentage of the range of GSIEVI changes exceeded $40 \%$ in most of the Hoh Xil nature reserve as the vegetation was sparse in 2000.

The areas where the decreasing trends were noted (at a significance level of 0.05) were mainly distributed in the Tanglha Mountains, south of the Tanglha Mountains and the region of permafrost thawing around rivers such as the Tongtian, Beilu and Tuotuo Rivers. GSIEVI decreases of up to 0.5 were observed in most of the area around Co Nag Lake.

According to the results, more than half $(57.1 \%)$ of our study area did not show a significant trend in GSIEVI, $23.6 \%$ of the area showed significant increasing trends in GSIEVI and the remaining 19.3\% of the area showed significant decreasing trends in GSIEVI (see Figure S5 in Supporting information). Approximately three-quarters $(72.4 \%)$ of the area where significant decreases in GSIEVI was observed 
was covered with alpine meadows dominated by Kobresia spp. and forbs. Of the area where vegetation showed significant increases, $42.8 \%$ and $43.4 \%$ was covered with alpine steppes that were dominated by grasses/Carex spp. and alpine meadows, respectively.

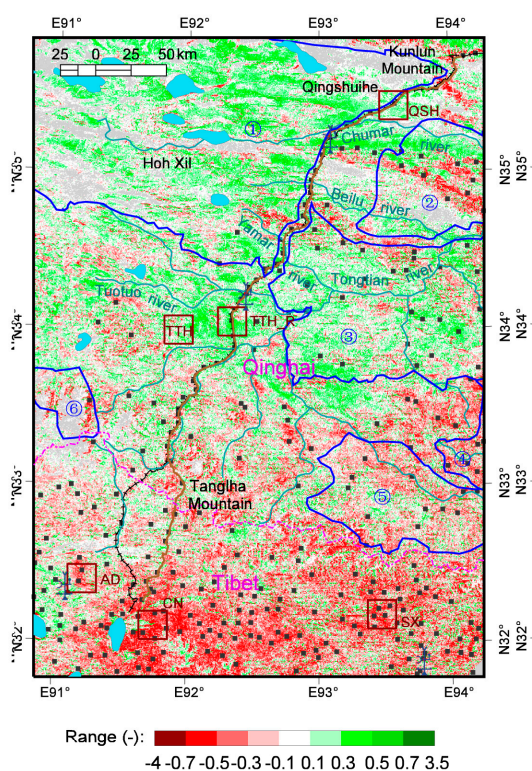

(a)

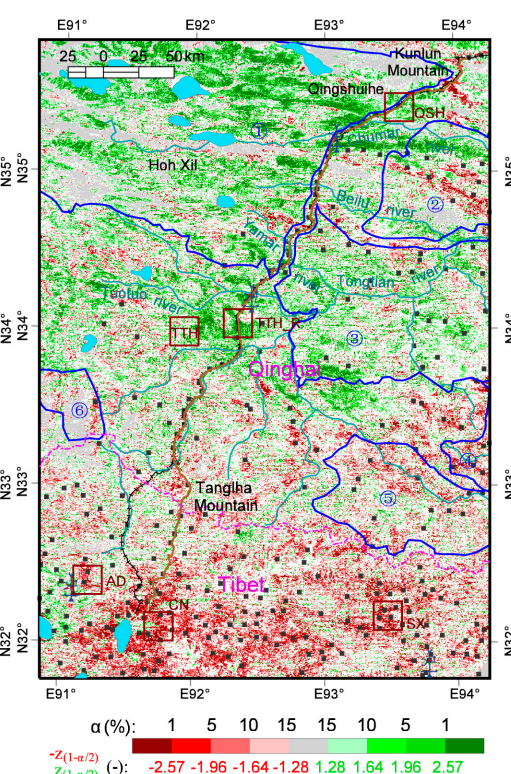

(b)

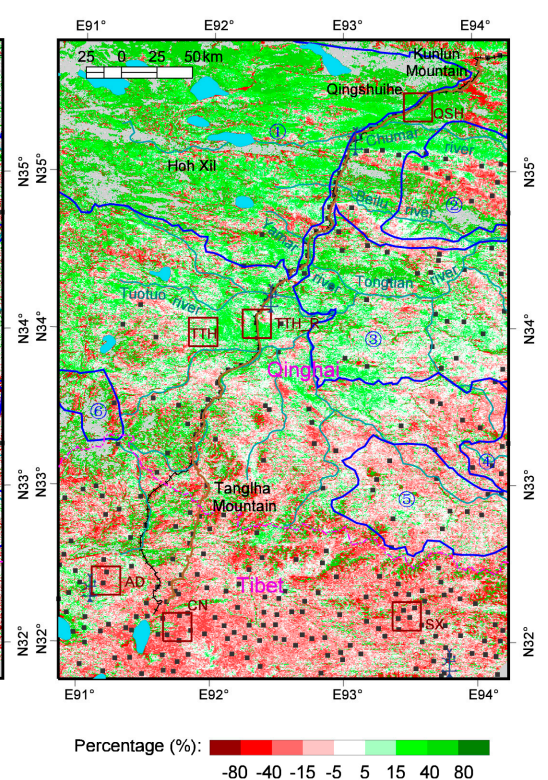

(c)

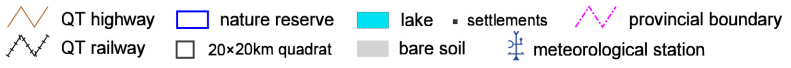

Figure 2. The range (a), significance (b) and percentage (c) of GSIEVI change during 2000 to 2016.

Within the GSIEVI time series, a pit point indicated that positive factors that could accelerate an increasing trend, change a decreasing trend into an increasing trend, or slow down a decreasing trend appeared during the following year. In contrast, a bump point indicated the appearance of negative factors that could slow down an increasing trend, turn an increasing trend into a decreasing trend, or accelerate a decreasing trend during the following year. Approximately 40.5\% of our study area displayed significant pit points in the GSIEVI time series, whereas $42.4 \%$ displayed significant bump points (at a significance level of 0.05 ; see Figure $3 b$ ). The areas that displayed pit points were mainly distributed in the Hoh Xil (see Figure 3a). These pit points in the GSIEVI changes occurred primarily after 2004 and especially in 2009 (19.3\% of all areas that displayed pit points), 2005 (16.4\%) and $2008(12.9 \%)$. The areas that displayed bump points were mainly distributed in the Tanglha Mountains and south of the Tanglha Mountains. These bump points occurred primarily after 2005, especially in 2012 (16.9\% of all areas that displayed a bump point), 2011 (15.5\%), 2010 (13.7\%) and $2006(11.6 \%)$.

Alpine meadows and alpine steppes were the two major vegetation types that were widely distributed in the study area. Since 2000, 25.5\% of the alpine meadows have decreased significantly and these areas accounted for $72.4 \%$ of the vegetation with a significant decreasing trend (see Table 1 ). In addition, the vegetation with a decreasing trend in GSIEVI was mainly distributed in the Tanglha Mountains and south of the Tanglha Mountains. A bump point in the GSIEVI decrease indicated that the decrease of GSIEVI would accelerate in the next year. About one-fifth $(21.5 \%)$ of the bump points appeared before 2006, especially in 2002 and 2004 (11.4\% in total). The causes of turning points will be treated in detail in the discussion section. 


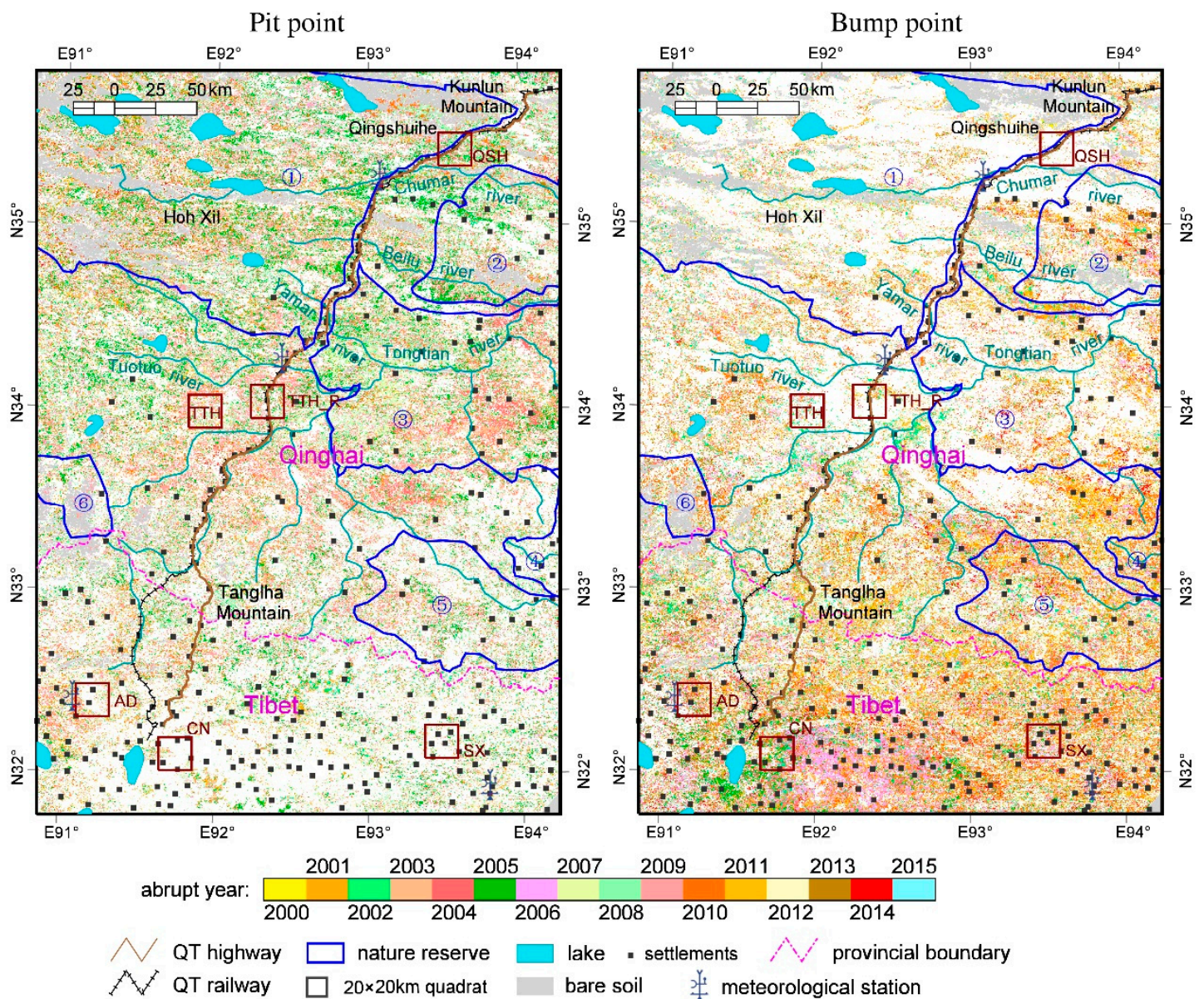

(a)

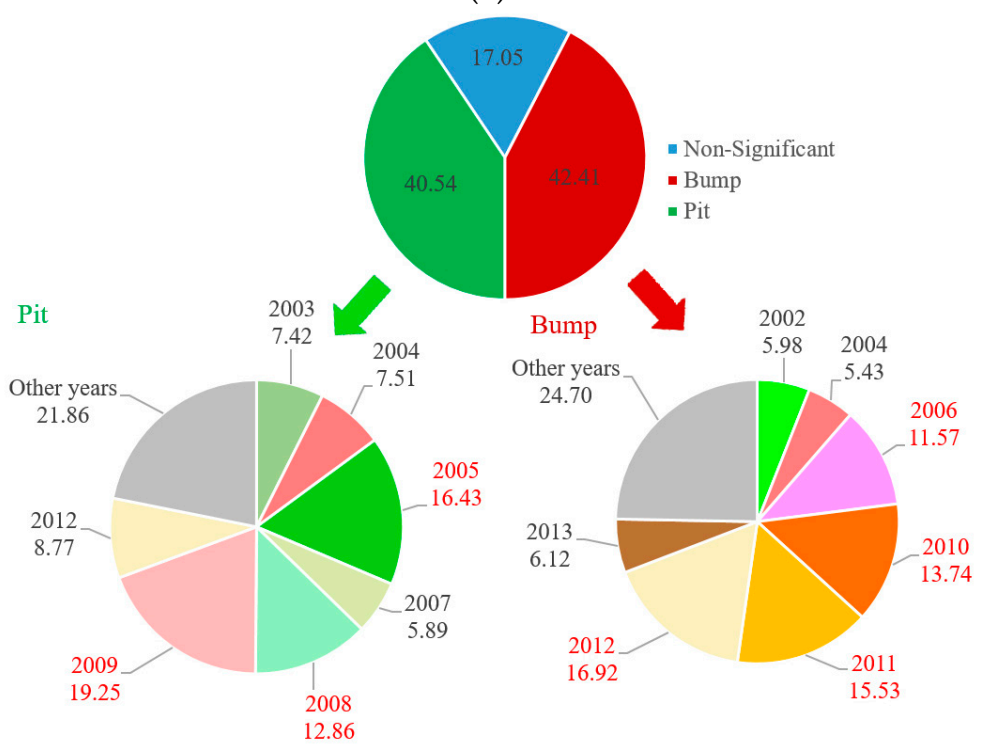

(b)

Figure 3. The pit and bump points during 2000 to 2016 (a) and the percentage distributions of turning points among years $(\mathbf{b})$. 
Table 1. Percentages (\%) of significant increase and decreases and bump points of growing season integrated EVI (GSIEVI) that appeared since 2006 for each vegetation type.

\begin{tabular}{cccccc}
\hline & Percentage of Each Type & \multicolumn{4}{c}{ Percentage in Each Vegetation Type (\%) } \\
\cline { 3 - 6 } in the Total Area (\%) & $\begin{array}{c}\text { Significant } \\
\text { Increase }\end{array}$ & $\begin{array}{c}\text { Significant } \\
\text { Decrease }\end{array}$ & $\begin{array}{c}\text { Bump Points } \\
\text { 2006-2009 }\end{array}$ & $\begin{array}{c}\text { Bump Points } \\
\text { since 2010 }\end{array}$ \\
\hline $\begin{array}{c}\text { Alpine sparse } \\
\text { vegetation }\end{array}$ & 6.21 & 18.20 & 19.97 & 12.81 & 26.61 \\
$\begin{array}{c}\text { Alpine cushion } \\
\text { vegetation }\end{array}$ & 7.56 & 27.44 & 10.63 & 8.13 & 14.81 \\
$\begin{array}{c}\text { Alpine steppes } \\
\text { Alpine meadows }\end{array}$ & 27.95 & 35.38 & 9.95 & 7.16 & 14.47 \\
$\begin{array}{c}\text { Subalpine } \\
\text { broadleaf }\end{array}$ & 52.90 & 19.11 & 25.46 & 12.98 & 30.51 \\
deciduous scrubs & 0.81 & 6.77 & 38.31 & 18.69 & 37.97 \\
\hline
\end{tabular}

\subsection{Correlations between Vegetation Growth (GSIEVI Change) and Two Climate Factors}

From 2000 to 2015, $P_{y}$ decreased at Amdo by $8.27 \mathrm{~mm}$ (the slope was $0.517 \mathrm{~mm} / \mathrm{y}$ ) and increased at Wudaoliang by $4.08 \mathrm{~mm}$ (the slope was $0.255 \mathrm{~mm} / \mathrm{y}$ ) and temperatures increased over the entire study area (see Table 2). At the four national meteorological stations, the annual average temperatures increased by similar amounts, i.e., approximately $0.8{ }^{\circ} \mathrm{C}$ (the slope varied from $0.048{ }^{\circ} \mathrm{C} / \mathrm{y}$ to $0.053{ }^{\circ} \mathrm{C} / \mathrm{y}$ ) over the past 16 years. However, the increase ranges of the $A T_{y}$ differed between the south and north of the Tanglha Mountains. At the Amdo and Suoxian stations, the $A T_{y}$ increased by four times as much as that in Wudaoliang and three times as much as that at the Tuotuo River. This result indicates that the number of days in which temperatures exceeded $0{ }^{\circ} \mathrm{C}$ increased much more rapidly at the Amdo and Suoxian stations than at Wudaoliang and the Tuotuo River.

Table 2. The change trends of rainfall, temperature and active accumulated temperature above $0{ }^{\circ} \mathrm{C}$ during 2000 to 2015, which were calculated using the similar equation as Equation (2).

\begin{tabular}{cccccc}
\hline \multicolumn{2}{c}{ Station Name } & Amdo & Suoxian & Wudaoliang & Tuotuo River \\
\hline \multicolumn{2}{c}{ Station ID } & $\mathbf{5 5 2 9 4}$ & $\mathbf{5 6 1 0 6}$ & $\mathbf{5 2 9 0 8}$ & $\mathbf{5 6 0 0 4}$ \\
\hline Range $_{R}$ & $\mathrm{~mm}$ & -8.27 & -0.06 & 4.08 & 0.59 \\
Range $_{\bar{T}}$ & ${ }^{\circ} \mathrm{C}$ & 0.81 & 0.84 & 0.80 & 0.77 \\
Range $_{A T}$ & ${ }^{\circ} \mathrm{C}$ & 133.37 & 125.24 & 30.92 & 46.29 \\
\hline
\end{tabular}

We calculated the multiple and partial correlation coefficients between the CGSIEVI values and the two climate factors $\left(P_{y}\right.$ and $\left.A T_{y}\right)$ at the different spatial scales from $500 \times 500 \mathrm{~m}$ to $20 \times 20 \mathrm{~km}$ within the six key regions. Three of the six key regions (QSH, TTH and TTH_R) were located in the hinterland of the predominantly continuous permafrost region on the QT Plateau (Figure 1). In these regions, the partial correlations between CGSIEVI values and two climate factors were always positive. Groundwater resources were abundant in the plains between the Kunlun Mountains and the Tanglha Mountains, especially around the Tuotuo River. Accordingly, the correlations between the CGSIEVI values and $P_{y}$ in the TTH and TTH_R key regions were insignificant from the scale of $500 \times 500 \mathrm{~m}$ to $20 \times 20 \mathrm{~km}$ (Figure 4). AD, CN and SX were located at the southern edge of the predominantly continuous permafrost region (Figure 1). As the temperature and the number of days when the temperature exceeded $0{ }^{\circ} \mathrm{C}$ increased, the permafrost began to degrade (permafrost table lowered). The moisture of the topsoil decreased; thus, the vegetation was affected. This limit of the active layer depth will be analyzed in the discussion section. Thus, the CGSIEVI values showed a significant negative correlation with $A T_{y}$ in the three key regions that were located at the southern edge of the predominantly continuous permafrost region. 


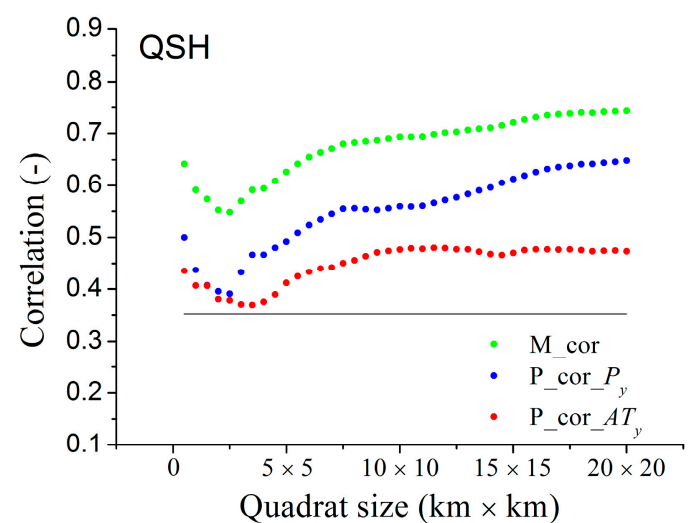

(a)

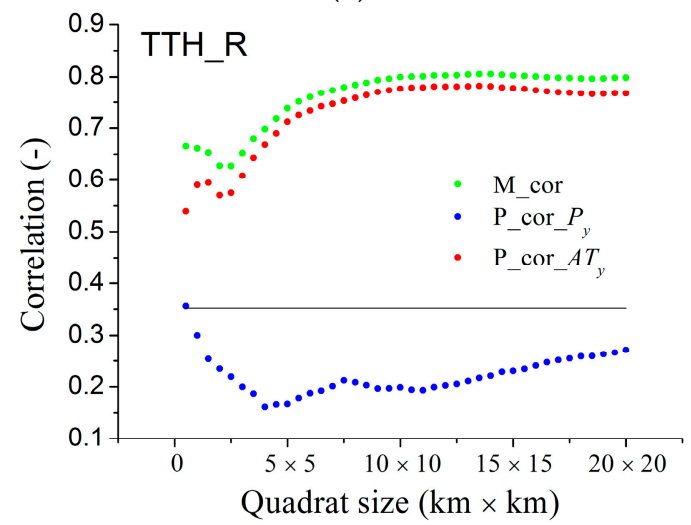

(c)

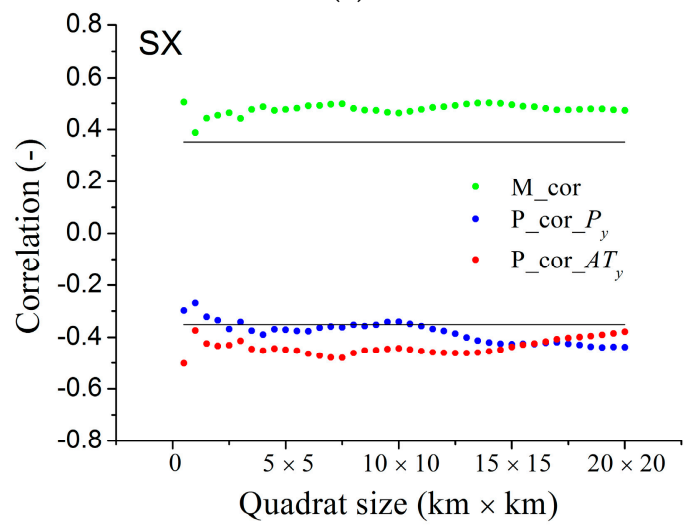

(e)

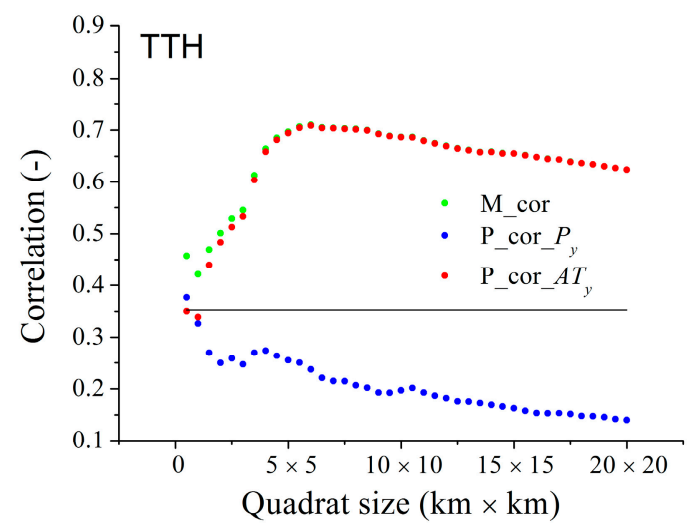

(b)

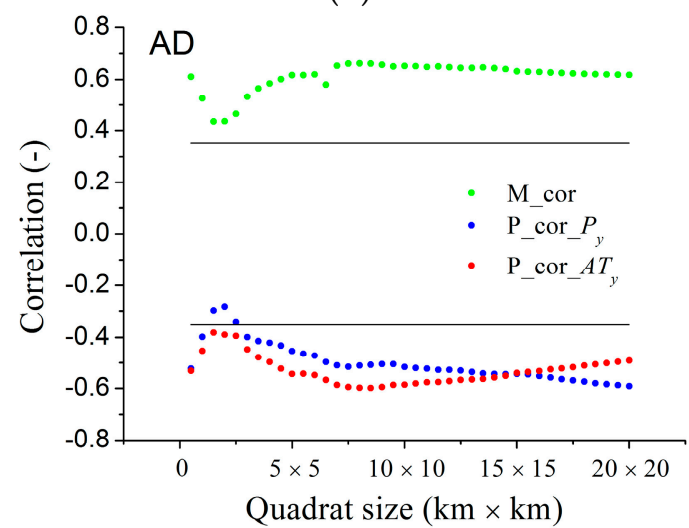

(d)

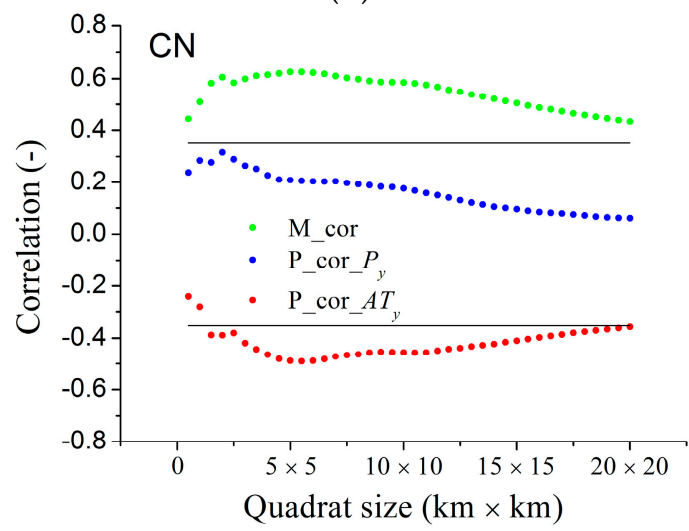

(f)

Figure 4. The multiple correlation (M_cor) and partial correlation (P_cor) for CGSIEVI and climate factors $P_{y}$ and $A T_{y}$ in (a) QSH, (b) TTH, (c) TTH_R, (d) AD, (e) SX and (f) CN key regions. Note: The black solid line indicates the threshold correlation coefficient value at $95 \%$ confidence.

\subsection{Effects of Human Activities}

\subsubsection{Renovation and Construction of the Qinghai-Tibet Highway and Railway}

The two roadside key regions, QSH and TTH_R, experienced the first renovation of the QT highway and the construction of the second phase of the QT railway. During the subgrade reinforcement project, soil was taken from the surrounding areas near the highway and filled into the subsidence subgrade, which destroyed the grass and shrub along the highway. Compared to subgrade reinforcement, pavement rebuilding will not damage the underlying surface and have less influence on vegetation growth. The construction of railway subgrade also damaged the grass and shrub nearby. 
Figure 5 shows the CEVI values within the two sets of roadside quadrats in the QSH key region and TTH_R key region and nature quadrats near QSH and TTH_R, respectively. The comparison of the CEVI values within the two sets of roadside quadrats and the nature quadrats nearby showed two types of impacts. First, engineering activities (the construction of the QT railway and the renovation of the QT highway) affected the growth of vegetation linearly along the QT Plateau Engineering Corridor. Given their linear nature, these engineering activities greatly influenced the growth of vegetation within a $3 \times 3 \mathrm{~km}$ area but did not influence the vegetation farther from the QT Plateau Engineering Corridor (beyond a $4 \times 4 \mathrm{~km}$ area). Second, the effects of engineering activities on the vegetation within the nested quadrats in QSH were greater than that within the nested quadrats in TTH as the vegetation around Qingshuihe was sparser than that near the Tuotuo River. The ecological environment around Qingshuihe is more fragile; therefore, once the vegetation had been damaged, the recovery cycle was longer.
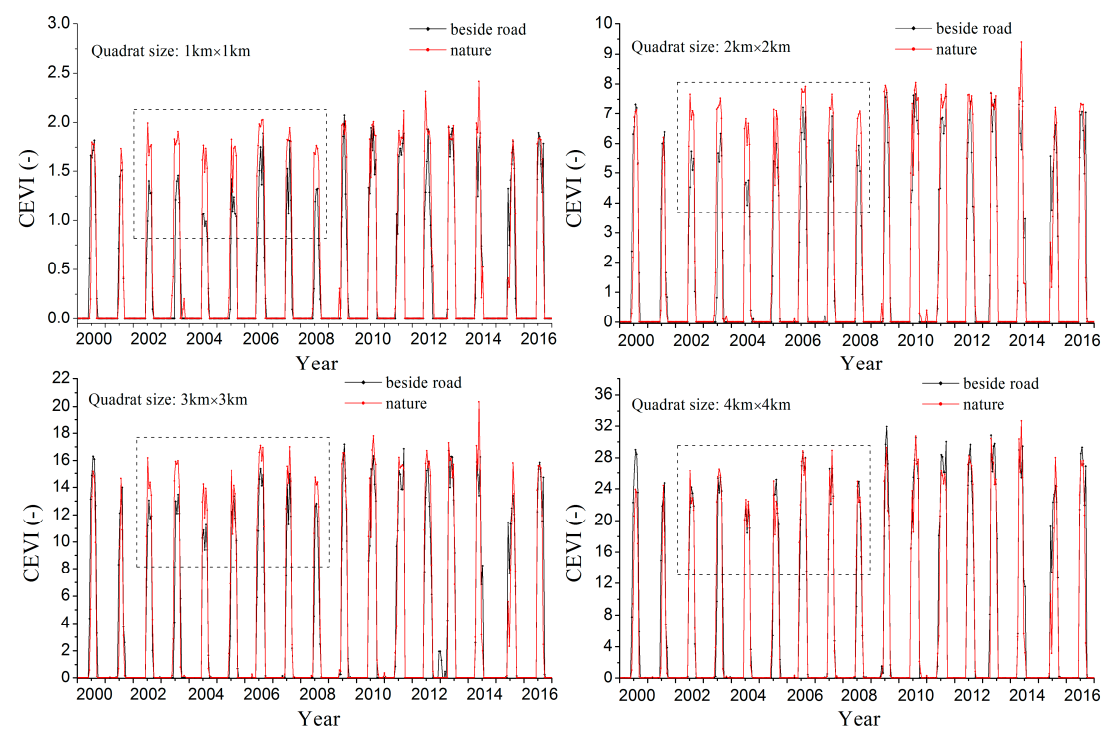

(a) QSH
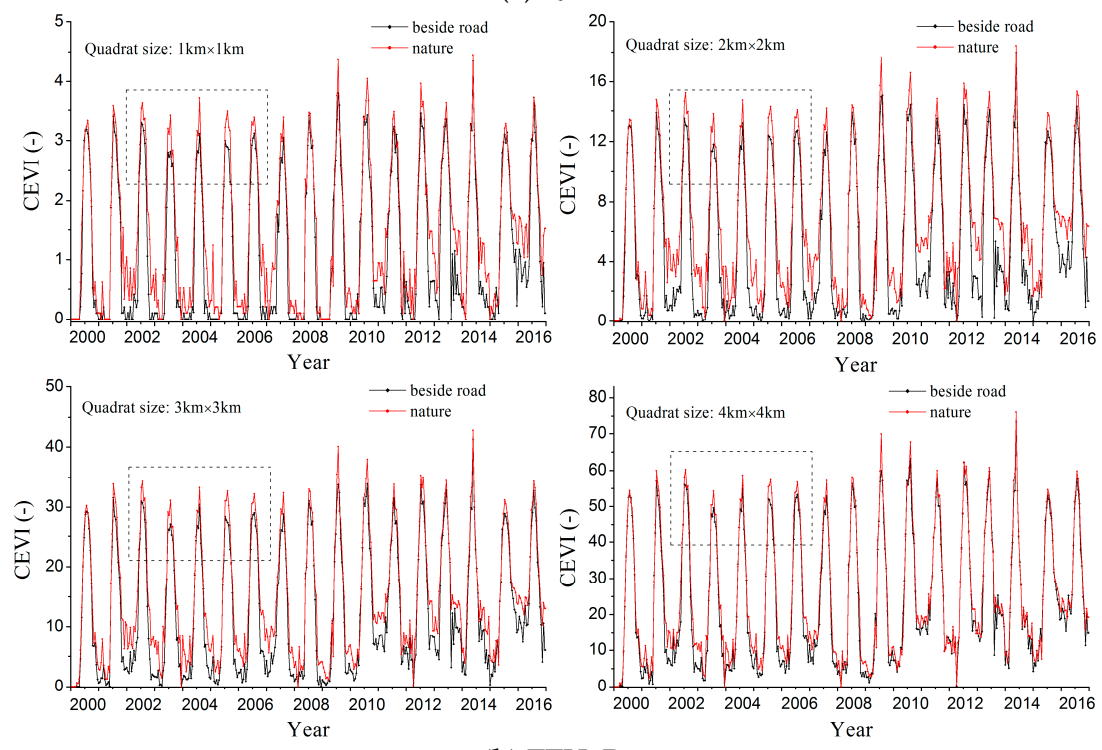

(b) TTH_R

Figure 5. Comparison of the cumulative EVI (CEVI) values within two sets of roadside quadrats in (a) QSH key region and (b) TTH_R key region and nature quadrats near QSH and TTH_R, respectively (quadrat size varied from $1 \times 1 \mathrm{~km}$ to $4 \times 4 \mathrm{~km}$ ). 


\subsubsection{Animal Husbandry}

The stock volume of total livestock in QH did not exceed 20 million after 2006. According to the results of the trend analysis and the abrupt change test, $16.43 \%$ of the vegetation displayed a pit point in 2005 and showed an increasing trend. The main reason for the occurrence of the pit points in 2005 was the livestock reduction in 2006. The vegetation began to increase from 2006. The yearly stock volume of total livestock in Tibet was greater than 23 million before 2012. The stock volume of goats and sheep decreased by 1.2 million and the total stock volume of herbivorous livestock in Tibet decreased to approximately 21.5 million. However, the decrease in vegetation in the Tanglha Mountains and the south of the Tanglha Mountains was caused by the degradation of the permafrost environment, as well as the presence of large livestock. The relationships between vegetation, the permafrost environment and animal husbandry will be analyzed in the discussion.

\subsubsection{Quantization of Impacts}

Based on the DMC method, the negative impact of linear infrastructural renovation on vegetation at different spatial scales from $500 \times 500 \mathrm{~m}$ to $4 \times 4 \mathrm{~km}$ were calculated using the CGSIEVI values and meteorological data covering the period from 2000 to 2007. Sparser vegetation is more fragile and is damaged more easily by engineering activities than denser vegetation. As the spatial scale increased, the negative impact of linear infrastructural renovation on vegetation decreased from $56.7 \%$ in QSH and $10.5 \%$ in TTH_R at a spatial scale of $500 \times 500 \mathrm{~m}$ to less than $1 \%$ at a spatial scale of $4 \mathrm{~km} \times 4 \mathrm{~km}$ (see Table 3). As the construction periods of the two engineering projects overlapped, the impacts of the two projects could not be separated.

The positive impact associated with the completion of the two engineering projects were calculated using the CGSIEVI values and meteorological data covering the period from 2002 to 2015 . Without the negative effects of the engineering projects, the vegetation began to recover and the positive impacts associated with the completion of the engineering projects were $60.3 \%$ and $13.2 \%$ in QSH and TTH_R, respectively, at a spatial scale of $500 \times 500 \mathrm{~m}$. However, the positive impacts were associated with both the completion of the two engineering projects and the reduction of livestock within a spatial scale of $4 \times 4 \mathrm{~km}$. In addition, the completion of the two engineering projects yielded a major contribution at a spatial scale of $500 \times 500 \mathrm{~m}$ and the reduction of livestock produced a major contribution at a spatial scale of $4 \times 4 \mathrm{~km}$.

Table 3. Impacts (\%) given by the implementation and completion of engineering projects.

\begin{tabular}{ccccc}
\hline \multirow{2}{*}{ Spatial Scale } & \multicolumn{2}{c}{ TTH_R } & QSH \\
\cline { 2 - 5 } & Road Repair & After Repair & Road Repair & After Repair \\
\cline { 2 - 5 } & Negative Impact (\%) & Positive Impact (\%) & Negative Impact (\%) & Positive Impact (\%) \\
\hline $\mathbf{5 0 0} \mathbf{~ m}$ & -10.47 & 13.63 & -56.70 & 60.27 \\
$\mathbf{1} \mathbf{~ k m}$ & -6.84 & 11.83 & -12.68 & 22.89 \\
$\mathbf{2} \mathbf{~ k m}$ & -5.12 & 9.28 & -3.91 & 17.23 \\
$\mathbf{3} \mathbf{~ k m}$ & -3.28 & 8.79 & -2.32 & 17.16 \\
$\mathbf{4} \mathbf{~ k m}$ & $<1$ & 9.38 & $<1$ & 16.69 \\
\hline
\end{tabular}

As the DMC method assumes the two variables being analyzed are proportional, it was not applied to the three key regions at the southern edge of the predominantly continuous permafrost region the Tanglha Mountains, which displayed significant negative correlations with the meteorological factors. Thus, the DMC method was applied to quantify the impacts associated with the different factors for QSH, TTH and TTH_R. However, the GSIEVI in the two key regions near the Tuotuo River showed insignificant correlations with precipitation given the abundant groundwater resources. Moreover, the effect of precipitation on vegetation displayed a time lag. Thus, the vegetation did not show a significant correlation with precipitation and the impacts from the other factors were quantified using the CGSIEVI values and $A T_{y}$. 
Figure 6 shows the impacts from different factors on vegetation growth (GSIEVI change) at different spatial scales. In the QSH key region (Figure 6a), the first factor was the recovery of vegetation after engineering projects; the second factor was livestock reduction and precipitation increase. In the TTH key region (Figure 6b), both factors were mixed factors, where the negative impact associated with permafrost degradation was mixed with the positive impacts associated with the livestock reduction. At different spatial scales, the impacts from permafrost degradation, the livestock reduction and the precipitation increase were different. In the TTH_R key region (Figure 6c), the first factor was the recovery of vegetation after the engineering projects; the second factor was mixed with the negative impact associated with permafrost degradation and the positive impacts associated with the livestock reduction.

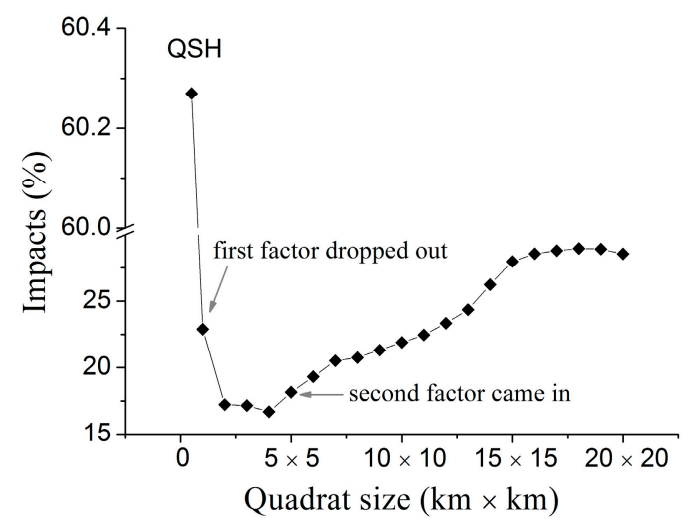

(a)

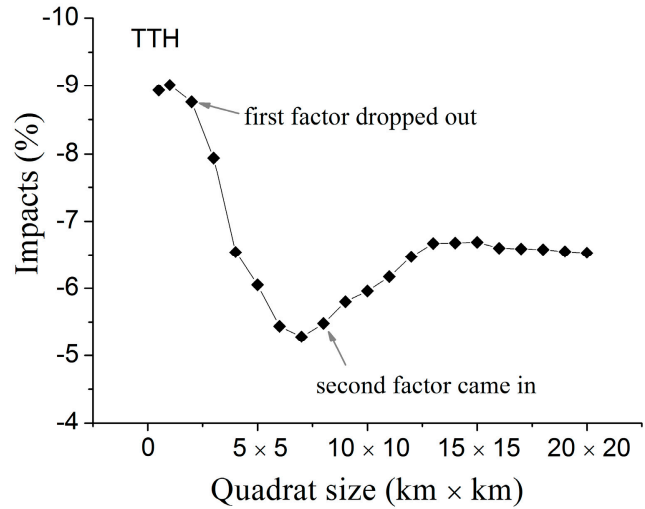

(b)

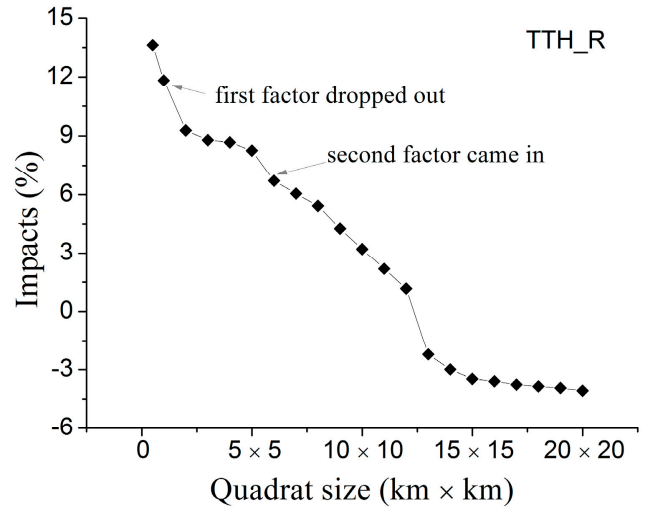

(c)

Figure 6. Impacts given by different factors on vegetation growth (GSIEVI change) at (a) the QSH key region, (b) the TTH key region and (c) the TTH_R key region.

Animal husbandry is a planar factor. The range of livestock activities determines the spatial scale of its effects on vegetation changes. In the QSH key region, the positive impact associated with the completion of engineering projects decreased as the sizes of the quadrats increased. When the sizes of the quadrats increased to $5 \times 5 \mathrm{~km}$ or larger, the other positive factors became important. As shown in Figure 3a, half of the vegetation in the QSH key region displayed a pit point in 2005 due to the livestock reduction in 2006. The positive impact associated with the decrease in livestock was approximately $28.7 \%$. In addition, the permafrost environment was relatively stable around Qingshuihe [26].

TTH and TTH_R were located within the region of permafrost thawing around the Tuotuo River. The TTH_R key region was mainly covered with alpine steppes. About a quarter (28.3\%) of the area in the northeast of the $20 \times 20 \mathrm{~km}$ quadrat of the TTH_R key region is covered with alpine meadows. Half of the TTH key region is covered with alpine meadows, whereas the other half is covered with 
alpine steppes. The positive impacts associated with the reduction in livestock in 2006 were mixed with the negative impact associated with permafrost degradation. In the TTH_R key region, the positive impact associated with the completion of the two engineering projects dropped and the reduction in livestock and the increase in precipitation gradually became associated as the major impact as the spatial scale increased from $500 \times 500 \mathrm{~m}$ to $5 \times 5 \mathrm{~km}$. At a spatial scale of $5 \times 5 \mathrm{~km}$, the negative effect caused by permafrost degradation was not represented. The positive impact associated with the reduction in livestock and the increase in precipitation was $8.3 \%$ at a spatial scale of $5 \times 5 \mathrm{~km}$. The negative impact appeared in the quadrat at a spatial scale of $6 \mathrm{~km} \times 6 \mathrm{~km}$. The positive impact was then offset gradually as the spatial scale increased and was completely offset at a spatial scale of $13 \times 13 \mathrm{~km}$. Finally, the positive impact was subtracted from the negative impact and $-4 \%$ was left at a spatial scale of $20 \times 20 \mathrm{~km}$. In the TTH key region, the positive impact of the drivers of vegetation change (e.g., reduction in grazing or increase in precipitation) on vegetation status was always less than the negative impact. The remaining negative impact was $-6.5 \%$ at a spatial scale of $20 \times 20 \mathrm{~km}$.

\section{Discussion}

To relate the abrupt point in vegetation growth (GSIEVI change) with the major events that occurred in the six key regions, we summarized the timeline of the major events for each key region. The time points involved in the discussion below refer to Figure 7.

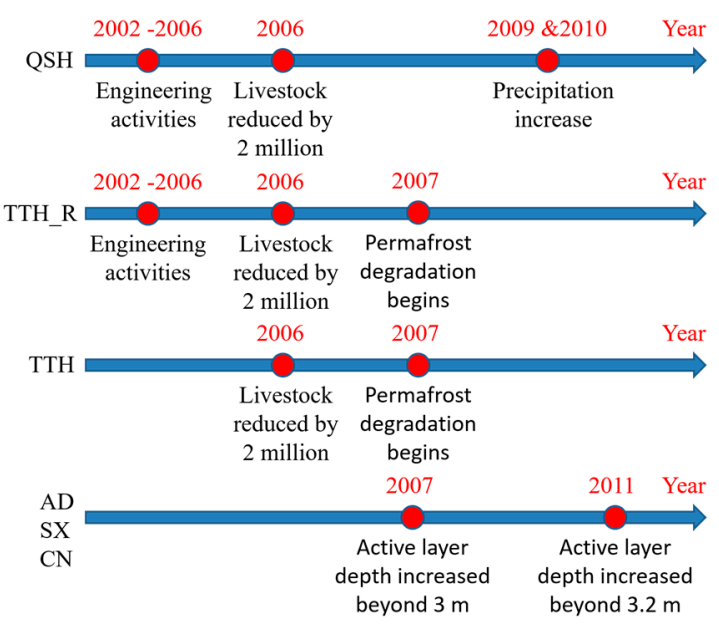

Figure 7. The timelines of major events occurred in the six key regions.

\subsection{Relationships among Climate Change, Permafrost Degradation, Vegetation Growth and Animal Husbandry}

The vegetation within our study area is mainly affected by climate change, animal husbandry and engineering activities. The freeze-thaw behavior of permafrost complicates the effect of climate on vegetation. Peng et al. indicated that over $80 \%$ of the vegetation on the QT Plateau showed a significant increasing trend from 1982 to 2003 and over $25 \%$ of the alpine meadows showed significant degradation [10]. Brucec et al. indicated that if the permafrost did not thaw, the vegetation greenness would increase with the rise of temperature in permafrost regions [28]. Since 2000, the temperature has continued to rise, especially at the southern edge of the predominantly continuous permafrost region. Between 2002 and 2012, the spring onset of soil thawing at a depth of $50 \mathrm{~cm}$ advanced by approximately 20 days within alpine meadows and 18 days within alpine steppes [12]. The $A T_{y}$ rose by more than $100{ }^{\circ} \mathrm{C}$ during the past 16 years, indicating that the number of days when temperature exceeded $0{ }^{\circ} \mathrm{C}$ has increased rapidly. Thus, in some studies, $A T_{y}$ was also used as a thawing index which is important in evaluating the areal distribution of permafrost and seasonally frozen ground [5,29]. Xu et al. indicated that the total area of permafrost decreased by $2.48 \times 10^{5} \mathrm{~km}^{2}$ on the QTP over the past three decades (1981 to 2010) [30]. Yin et al. indicated that the active layer depth around the 
Beilu River (in the northern part of our study area) increased by at least $42 \mathrm{~cm}$ from 2003 to 2016 [13]. This agrees with our findings. According to the in situ soil temperature observations measured near Amdo County, the active layer depth underwent two periods of rapid increase (indicated by the light pink and rose pink bands in Figure 8). The ground temperature observation site is located $18 \mathrm{~km}$ north of the CN key region. The increasing trend in $A T_{y}$ in the Amdo and Suoxian Counties disturbed the stability of the permafrost environment and caused permafrost degradation. The alpine cold grassland ecosystems found within the permafrost area on the QT Plateau are closely associated with permafrost conditions [11]. When permafrost degradation occurs, the soil loses its ability to block the infiltration of water and becomes strongly hydraulically conductive. The increase in the depth of the active layer caused the upper soil layer to become drier; subsequently, these changes inhibit the growth of alpine meadow vegetation, which has shallow root systems [16]. Cheng and Jin also indicated that when permafrost is thawed or warmed to the melting point of water, (open) talik channels can be formed or enlarged and the recharge from surface waters and supra permafrost water will facilitate to deep groundwater, which will result in a decline in surface waters and the supra-permafrost water [31]. According to Figure 8, the variation in GSIEVI was sensitive to the active layer depth of $2.7 \mathrm{~m}, 3 \mathrm{~m}$ and $3.2 \mathrm{~m}$. When the active layer depth dropped below $2.7 \mathrm{~m}$ but remained above $3 \mathrm{~m}$ (the depth of the yellow range in Figure 8), the thawing of permafrost caused moisture stress for shallow rooted plants due to a reduction in surficial moisture. Thus, the alpine meadows began to degenerate (see GSIEVI data in Figure 8). When the active layer depth dropped below $3 \mathrm{~m}$, increasing areas covered with alpine meadows showed accelerated degradation. Thus, the active layer depth of $3 \mathrm{~m}$ to $3.2 \mathrm{~m}$ (i.e., the depth of the orange range in Figure 8) represents a limiting depth for vegetation, especially alpine meadows, in our study area. The increase in the active layer depth in 2003 and 2005 disturbed the balance between the permafrost environment and the vegetation and led to the accelerated degradation of the vegetation. The $78.5 \%$ of the bump points have appeared since 2006, especially in 2006, 2010, 2011 and 2012. The increase in the active layer depth in 2007 and 2011 caused accelerated degradation of a wide range of vegetation. The permafrost degradation after 2006 affected $43.5 \%$ of the alpine meadows and $21.6 \%$ of the alpine steppes. In addition, increasingly large areas of vegetation began to either degrade, or show increased rates of degradation after 2007. The problem of desertification is even more serious than before. Wu et al. used nine sites of soil temperatures in Honglianghe River Basin along the QT Highway to prove the traditional geocryological knowledge, which states that desertification will accelerate the degradation of permafrost under most circumstances [32]. However, the global temperature is expected to continue to increase [33]. The region along the QT railway would warm $2.8-3.0^{\circ} \mathrm{C}$ by the middle of the 21 st century and $3.8-4.8^{\circ} \mathrm{C}$ by the end of the 21 st century [34]. Under climate warming scenarios, the permafrost distribution on the QT Plateau is expected to shrink toward the northwest in the future [35]. Desertification and degradation of permafrost will promote each other in the case of overgrazing.

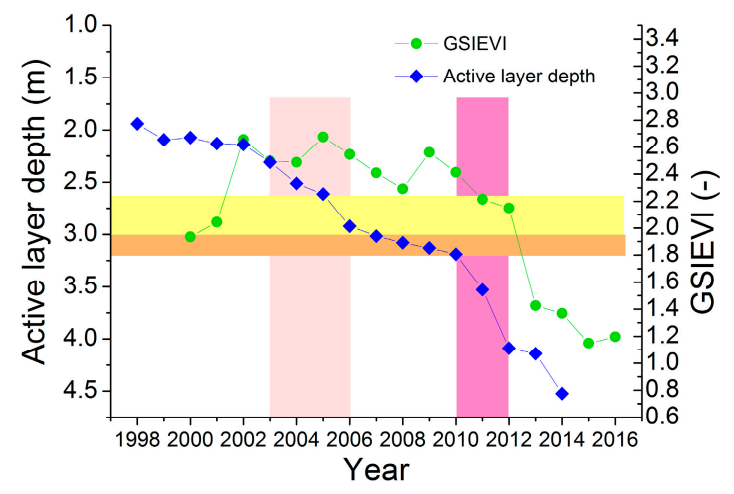

Figure 8. The active layer depth and GSIEVI near the south edge of the predominantly continuous permafrost region during 1998 to 2014 . Note: The ground temperature observation site is located within the GSIEVI pixel. 
Most of the area that displayed significantly increasing trends in the GSIEVI is located in the Hoh Xil. The livestock reduction in 2006 led to the development of a pit point in 2005. The development of pit points in 2008 and 2009 was mainly caused by the precipitation increase in 2009 and 2010. The precipitation at Wudaoliang station (52908) was $427 \mathrm{~mm}$ and $382 \mathrm{~mm}$ in 2009 and 2010, respectively, which exceeded the multi-year average precipitation by $85 \mathrm{~mm}$ and $40 \mathrm{~mm}$, respectively. Approximately a third (35.4\%) of the alpine steppes displayed improvement because of the reduction in livestock and the increase in precipitation in these areas. However, the yearly stock volume of total herbivorous livestock remained above 23 million in Tibet and did not decrease until 2012, the degradation of vegetation from 2000 to 2012 in the Tanglha Mountains and south of the Tanglha Mountains was caused by the heavy grazing in Tibet as well as the degradation of permafrost. The DMC method could not separate the impacts from different factors which appeared at the same time. Given that the degradation of permafrost and overgrazing often operate together, it is virtually impossible to separate the impact of the degradation of permafrost on vegetation growth from that of overgrazing. In addition, the reduction in livestock (6.4\% of the stock volume) in 2012 did not stop the accelerated degradation of vegetation.

\subsection{Scale Effect}

The TTH and TTH_R key regions are located in the region of permafrost thawing around the Tuotuo River. The impacts from the permafrost degradation and the sudden increase in precipitation was also calculated based on the DMC method. In fact, the permafrost degradation was mainly caused by the rise in temperature. However, the vegetation (GSIEVI) that had a significant positive correlation with $A T_{y}$ was mixed with the vegetation that was affected by permafrost degradation in these two key regions. As the vegetation (GSIEVI) did not show a significant correlation with precipitation, the impacts were quantified by applying the DMC method to the CGSIEVI values and $A T_{y}$. Thus, the contribution associated with the sudden increases in precipitation could also be considered. The reduction in livestock in 2006 resulted in improvements in the alpine steppes (note the pit points in 2005 within the two key regions). The increase in precipitation in 2009 and 2010 promoted vegetation growth (note the pit points in 2008 and 2009). The gradual thawing of the permafrost led to the degradation of the alpine meadows (note the bump points in 2010, 2011 and 2012). Thus, the positive impacts associated with the reduction in livestock and the increase in precipitation were mixed with the negative impacts caused by permafrost degradation.

The main human activities that affected vegetation growth were engineering activities and animal husbandry. The range of the negative effects caused by engineering activities was very limited and the negative impacts produced by engineering activities diminished quickly as the spatial scale increased. If the spatial scale was beyond $4 \times 4 \mathrm{~km}$, the negative impacts produced by engineering activities could be omitted. Thus, the negative impacts produced by engineering activities are suggested to be analyzed under the spatial scale of $4 \times 4 \mathrm{~km}$.

The effect of livestock on vegetation was planar. The impacts of livestock on the vegetation increased as the effect gradually entered into each quadrat. When the spatial scale of the effect from animal husbandry was equivalent to the size of the quadrat, the impacts did not increase further. The impacts then dropped when the size of the quadrat became much bigger than the spatial scale of the effect from animal husbandry. The QSH key region provided a particularly good example of this point. Thus, the effect from animal husbandry is suggested to be analyzed under the spatial scale of $15 \times 15 \mathrm{~km}$ in the QSH key region.

In the TTH and TTH_R key region, the negative impact associated with permafrost degradation were mixed with the positive impacts associated with livestock reduction. The positive impact decreased and the negative impact increased gradually as the spatial scale increased. When the spatial scale of the effect from permafrost degradation was much bigger than that of the effect from animal husbandry, the impacts remained stable. Thus, the negative impact associated with permafrost 
degradation is suggested to be analyzed over the spatial scale of $13 \times 13 \mathrm{~km}$ in the TTH key region and $14 \times 14 \mathrm{~km}$ in the TTH_R key region, respectively.

\subsection{Growing Season Integrated Enhanced Vegetation Index and Cumulative GSIEVI within Particular Areas}

The index used as an annual index of vegetation growth is important in the trend analysis. Zhang et al. used the averaged NDVI in the growing season to learn the greenness trend in the QT Plateau. Their results indicated that the most grasslands in the same region as our study area did not show a significant trend from 2000 to 2009 at the confidence level of 0.1 [36]. Compared to the mean value of vegetation index (VI; in our study EVI was used) during the growing season, the growing season integrated VI (GSIEVI in our study) enhanced the annual variability in the VI time series. The more EVIs whose value exceeded 0.1 during the growing season, the larger the GSIEVI becomes cumulated (see Figure 9a,b). However, the number of EVI whose value exceeded 0.1 has not been considered in the calculation of the mean value of EVI during the growing season. The CGSIEVI enhanced the annual variability in the EVI time series within a certain area (see Figure 9c,d). Due to the sparse vegetation cover in the study area, the use of average GSIEVI values to characterize particular areas would be weakened by the low GSIEVI values of bare soil.

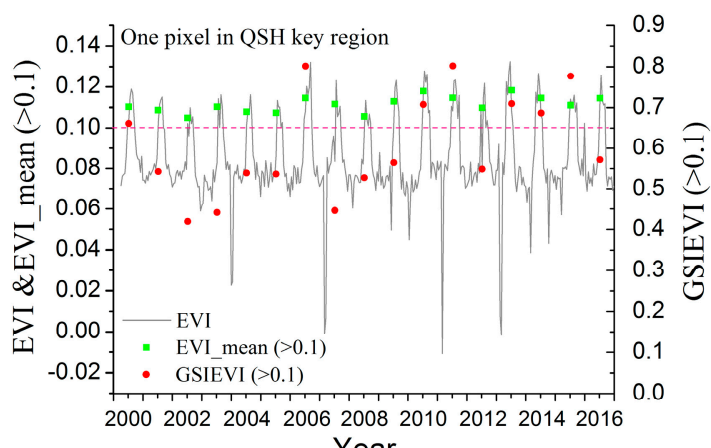

Year

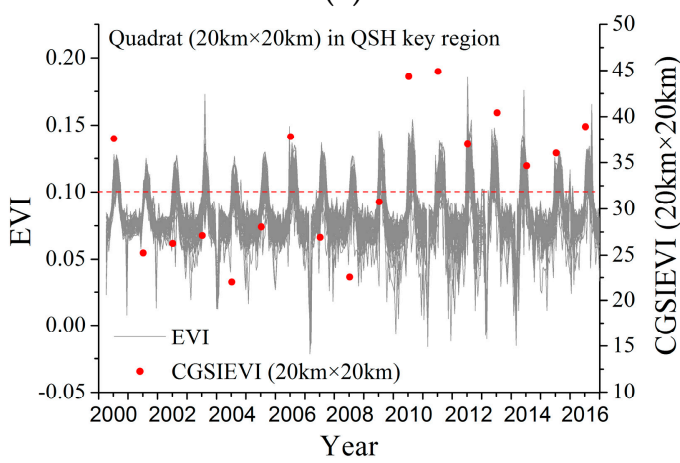

(c)

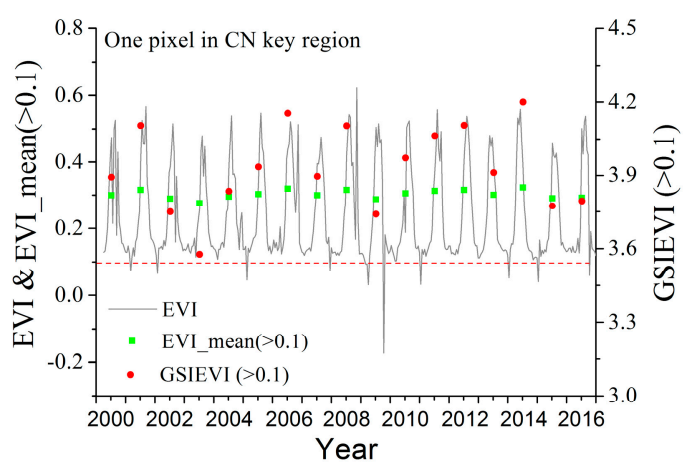

(b)

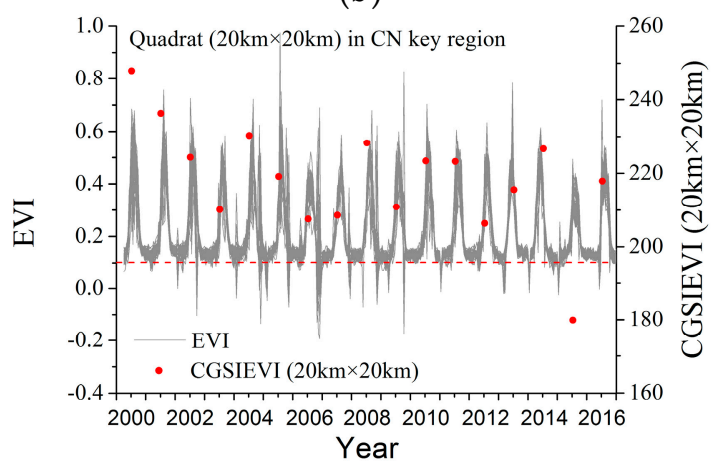

(d)

Figure 9. Enhanced Vegetation Index (EVI) time series, mean value of EVI during growing season (EVI_mean) and GSIEVI for one pixel in the (a) QSH and (b) CN key region; EVI time series and CGSIEVI for 64 pixels within the quadrat of $20 \times 20 \mathrm{~km}$ in the (c) QSH and (d) CN key regions.

\section{Conclusions}

From 2000 to 2016, 23.6\% of the vegetation showed a significant increasing trend. In addition, the vegetation that displayed a significant increasing trend was mainly distributed in the Hoh Xil. The increases in vegetation were mainly caused by the reduction in the yearly stock volume of total herbivorous livestock in Qinghai Province in 2006 (which decreased from 22 million to less than 20 million) and the increase in precipitation in 2009 and 2010 (which exceeded the multi-year average precipitation by $85 \mathrm{~mm}$ and $40 \mathrm{~mm}$, respectively). Approximately one-fifth (19.3\%) of the vegetation 
showed a decreasing trend due to permafrost degradation and overgrazing. Moreover, $72.4 \%$ of the vegetation that displayed a decreasing trend was made up of alpine meadows. Due to the permafrost degradation, which was caused by the increases in temperature, the topsoil water infiltration increased. As a result, the vegetation retreated, especially in the alpine meadows, which has shallow root systems. Moreover, the results indicated that an active layer depth of $3 \mathrm{~m}$ to $3.2 \mathrm{~m}$ represented a limiting depth for alpine meadows. Overgrazing was another cause of vegetation degradation and this factor tended to work together with the permafrost degradation. Since 2007, increasing areas of vegetation, especially alpine meadows, have begun to either degenerate or experience more rapid degradation. Over half of our study area is covered with alpine meadows, which are the main source of food for herbivores in this region. The problem of desertification is even more serious than before.

Supplementary Materials: The following are available online at www.mdpi.com/2072-4292/10/1/95/s1; Figure S1: Soil temperature observations measured near Amdo County during 1998 to 2014; Figure S2: Livestock numbers of Qinghai Province (a) and Tibet (b) during 2000 to 2015; Figure S3: The $A T_{y}(\mathbf{a})$ and $P_{y}$ values (b) from 2000 to 2015 at the 4 meteorological stations; Figure S4: DMCs for quadrats in the QSH key region at scales of (a) $500 \times 500 \mathrm{~m},(\mathbf{b}) 10 \times 10 \mathrm{~km}$ and (c) $20 \times 20 \mathrm{~km}$; Figure S5: Summary statistics on the change trends for different vegetation types.

Acknowledgments: This work was supported by the New Star Project of Youth Science and Technology of Shaanxi Province in China (grant 2016KJXX-91), the National Natural Science Foundation of China (grant 41401412) and the Opening Foundation of the State Key Laboratory of Highway Engineering Safety and Health in Cold and High-Altitude Regions of China. The map of vegetation types and permafrost distribution on the QT Plateau were provided by the Environmental and Ecological Science Data Center for West China, National Natural Science Foundation of China (http:/ / westdc.westgis.ac.cn).

Author Contributions: Yi Song and Haibo Wang conceived and designed the analysis methods; Yi Song analyzed the remotely sensed data and meteorological data; Long Jin provided the soil temperature observations near Amdo County and analyzed these data; Yi Song and Long Jin wrote the manuscript.

Conflicts of Interest: The authors declare no conflict of interest.

\section{References}

1. Piao, S.L.; Fang, J.Y.; He, J.S. Variations in vegetation net primary production in the Qinghai-Xizang Plateau, China, from 1982 to 1999. Clim. Chang. 2006, 74, 253-267. [CrossRef]

2. Hu, C.J.; Fu, B.J.; Liu, G.H.; Jin, T.T.; Guo, L. Vegetation patterns influence on soil microbial biomass and functional diversity in a hilly area of the Loess Plateau, China. J. Soils Sediment. 2010, 10, 1082-1091. [CrossRef]

3. Fu, B.J.; Li, S.G.; Yu, X.B.; Yang, P.; Yu, G.R.; Feng, R.G.; Zhuang, X.L. Chinese ecosystem research network: Progress and perspectives. Ecol. Complex. 2010, 7, 225-233. [CrossRef]

4. Kelly, M.; Tuxen, K.A.; Stralberg, D. Mapping changes to vegetation pattern in a restoring wetland: Finding pattern metrics that are consistent across spatial scale and time. Ecol. Indic. 2011, 11, 263-273. [CrossRef]

5. King, L.; Herza, T.; Hartmann, H.; Hof, R.; Jiang, T.; Ke, C.; Wei, Z.; Liu, J.; Yi, C. The PACE monitoring strategy: A concept for permafrost research in Qinghai-Tibet. Quat. Int. 2006, 154-155, 149-157. [CrossRef]

6. Jin, R.; Li, X.; Che, T. A decision tree algorithm for surface soil freeze/thaw classification over China using SSM/I brightness temperature. Remote Sens. Environ. 2009, 113, 2651-2660. [CrossRef]

7. Cheng, G.D.; Wu, T.H. Responses of permafrost to climate change and their environmental significance, Qinghai-Tibet Plateau. J. Geophys. Res. 2007, 112, F02S03. [CrossRef]

8. Zhuang, Q.L.; Romanovsky, V.E.; McGuire, A.D. Incorporation of a permafrost model into a large-scale ecosystem model: Evaluation of temporal and spatial scaling issues in simulating soil thermal dynamics. J. Geophys. Res. 2001, 106, 33649-33670. [CrossRef]

9. Zhuang, Q.; He, J.; Lu, Y.; Ji, L.; Xiao, J.; Luo, T. Carbon dynamics of terrestrial ecosystems on the Tibetan Plateau during the 20th century: An analysis with a process-based biogeochemical model. Glob. Ecol. Biogeogr. 2010, 19, 649-662. [CrossRef]

10. Peng, J.; Liu, Z.H.; Liu, Y.H.; Wu, J.S.; Han, Y. Trend analysis of vegetation dynamics in Qinghai-Tibet Plateau using Hurst Exponent. Ecol. Indic. 2012, 14, 28-39. [CrossRef] 
11. Wang, G.X.; Li, Y.S.; Chen, L. Impacts of permafrost changes on alpine ecosystem in Qinghai-Tibet Plateau. Sci. China Ser. D-Earth Sci. 2006, 49, 1156-1169. [CrossRef]

12. Wu, Q.B.; Hou, Y.D.; Yun, H.B.; Liu, Y.Z. Changes in active-layer thickness and near-surface permafrost between 2002 and 2012 in alpine ecosystems, Qinghai-Xizang (Tibet). Glob. Planet. Chang. 2015, 124, 149-155. [CrossRef]

13. Yin, G.A.; Niu, F.J.; Li, Z.J.; Luo, J.; Liu, M.H. Effects of local factors and climate on permafrost conditions and distribution in Beiluhe basin, Qinghai-Tibet Plateau, China. Sci. Total Environ. 2017, 581-582, 472-485. [CrossRef] [PubMed]

14. Jin, R.; Zhang, T.J.; Li, X.; Yang, X.G.; Ran, Y.H. Mapping Surface Soil Freeze-Thaw Cycles in China based on SMMR and SSM/I Brightness Temperatures from 1978-2008. Arct. Antarct. Alp. Res. 2015, 47, $213-229$. [CrossRef]

15. Wang, G.X.; Li, Y.S.; Wang, Y.B.; Wu, Q.B. Effects of permafrost thawing on vegetation and soil carbon pool losses on the Qinghai-Tibet Plateau, China. Geoderma 2008, 143, 143-152.

16. Xue, X.; Guo, J.; Han, B.S.; Sun, Q.W.; Liu, L.C. The effect of climate warming and permafrost thaw on desertification in the Qing-Tibetan Plateau. Geomorphology 2009, 108, 182-190. [CrossRef]

17. Hou, X.Y.; Sun, S.Z.; Zhang, J.W. Map of Vegetation Type in People's Republic of China $(1: 4,000,000)$; Sinomap Press: Beijing, China, 1979.

18. Li, S.; Cheng, G.D. Map of Permafrost Distribution on the Qinghai-Tibet Plateau (1:3,000,000); Gansu Culture Press: Lanzhou, China, 1996.

19. Stow, D.; Daeschner, S.; Hope, A.; Douglas, D.; Perersen, A.; Myneni, R.; Zhou, L.; Oechel, W. Variability of the Seasonally Integrated Normalized Difference Vegetation Index Across the North Slope of Alaska in the 1990s. Int. J. Remote Sens. 2003, 24, 1111-1117. [CrossRef]

20. Ma, M.G.; Veroustraete, F. Interannual variability of vegetation cover in the Chinese Heihe River Basin and its relation to meteorological parameters. Int. J. Remote Sens. 2006, 27, 3473-3486. [CrossRef]

21. Sicard, P.; Mangin, A.; Hebel, P.; Mallea, P. Detection and estimation trends linked to air quality and mortality on French Riviera over the 1990-2005 period. Sci. Total Environ. 2010, 408, 1943-1950. [CrossRef] [PubMed]

22. Zhang, A.J.; Zheng, C.M.; Wang, S.; Yao, Y.Y. Analysis of streamflow variations in the Heihe River Basin, northwest China: Trends, abrupt changes, driving factors and ecological influences. J. Hydrol. 2015, 3, 106-124. [CrossRef]

23. Zhang, B.Q.; He, C.S.; Burnham, M.; Zhang, L.H. Evaluating the coupling effects of climate aridity and vegetation restoration on soil erosion over the Loess Plateau in China. Sci. Total Environ. 2016, 539, 436-449. [CrossRef] [PubMed]

24. Pettitt, A.N. A non-parametric approach to the change point problem. Appl. Stat. 1979, 28, 126-135. [CrossRef]

25. Kisi, O.; Ay, M. Comparison of Mann-Kendall and innovative trend method for water quality parameters of the Kizilirmak River, Turkey. J. Hydrol. 2014, 513, 362-375. [CrossRef]

26. Wang, S.; Fu, B.J.; Piao, S.L.; Lv, Y.H.; Ciais, P.; Feng, X.M.; Wang, Y.F. Reduced sediment transport in the Yellow River due to anthropogenic changes. Nat. Geosci. 2016, 9, 38-41. [CrossRef]

27. Yang, H.B.; Kang, W.L.; Yu, Y.; Yin, X.; Wang, P.X.; Zhang, X.F. A new approach to evaluate the particle growth and sedimentation of dispersed polymer microsphere profile control system based on multiple light scattering. Powder Technol. 2017, 315, 477-485. [CrossRef]

28. Brucec, F.; Marcmacias, F.; Pentti, Z. Russian Arctic warming and 'greening' are closely tracked by tundra shrub willows. Glob. Chang. Biol. 2010, 16, 1542-1554.

29. Peng, H.; Ma, W.; Mu, Y.H.; Jin, L.; Yuan, K. Degradation characteristics of permafrost under the effect of climate warming and engineering disturbance along the Qinghai-Tibet Highway. Nat. Hazards 2015, 75, 2589-2605. [CrossRef]

30. Xu, X.M.; Zhang, Z.Q.; Wu, Q.B. Simulation of permafrost changes on the Qinghai-Tibet Plateau, China, over the past three decades. Int. J. Digit. Earth 2017, 10, 522-538. [CrossRef]

31. Cheng, G.D.; Jin, H.J. Permafrost and groundwater on the Qinghai-Tibet Plateau and in northeast China. Hydrogeol. J. 2013, 21, 5-23. [CrossRef]

32. Wu, Q.B.; Yu, W.B.; Jin, H.J. No protection of permafrost due to desertification on the Qinghai-Tibet Plateau. Sci. Rep. 2017, 7, 1544. [CrossRef] [PubMed] 
33. IPCC (Intergovernmental Panel on Climate Change). Climate Change 2013: The Physical Science Basis: Contribution of Working Group I to the Fifth Assessment Report of the Intergovernmental Panel on Climate Change; Cambridge University Press: Cambridge, UK, 2013.

34. Xu, Y.; Ding, Y.H.; Li, D.L. Climate Change over Qinghai and Xizang in 21st Century. Plateau Meteorol. 2003, 22, 451-457.

35. Lu, Q.; Zhao, D.S.; Wu, S.H. Simulated responses of permafrost distribution to climate change on the Qinghai-Tibet Plateau. Sci. Rep. 2017, 7, 3845. [CrossRef] [PubMed]

36. Zhang, L.; Guo, H.D.; Ji, L.; Lei, L.P.; Wang, C.Z.; Yan, D.M.; Li, B.; Li, J. Vegetation greenness trend (2000 to 2009) and the climate controls in the Qinghai-Tibetan Plateau. J. Appl. Remote Sens. 2013, 7, 1-17. [CrossRef]

2018 by the authors. Licensee MDPI, Basel, Switzerland. This article is an open access article distributed under the terms and conditions of the Creative Commons Attribution (CC BY) license (http://creativecommons.org/licenses/by/4.0/). 